\title{
Role of Metabolically Active Drugs in the Management of Ischemic Heart Disease
}

\author{
Richard S. Schofield and James A. Hill \\ Division of Cardiovascular Medicine, University of Florida College of Medicine, Gainesville, Florida, USA
}

\section{Contents}

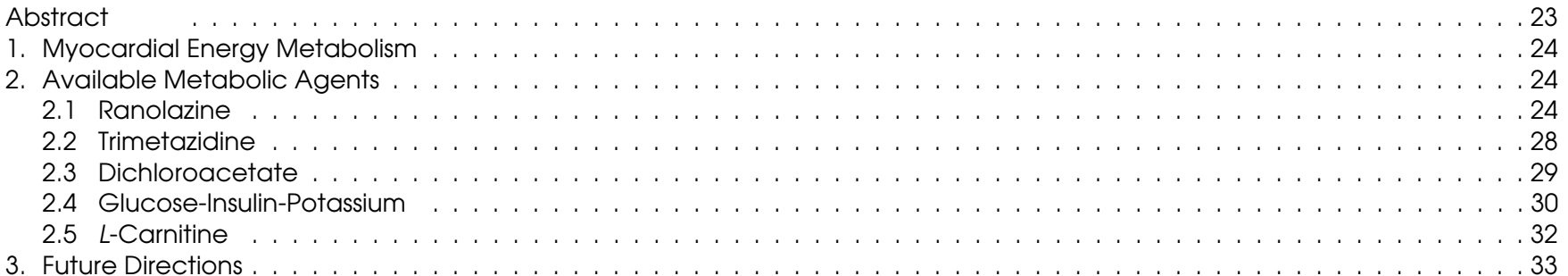

\section{Abstract}

This article reviews the fundamentals of myocardial energy metabolism and selectively outlines the use of several metabolically active drug therapies in the treatment of ischemic heart disease. These drugs - ranolazine, trimetazidine, dichloroacetate (DCA), glucose-insulin-potassium (GIK) solutions, and $L$-carnitine - have mechanisms of action distinct from traditional anti-ischemic drugs. These agents work by shifting myocardial energy metabolism away from fatty acids toward glucose as a source of fuel. Because these agents are well tolerated and do not affect heart rate or blood pressure, they conceivably could supplement traditional anti-ischemic drug therapy with little risk. The background, rationale for use, and published literature on each agent is reviewed, and the outcomes of pertinent clinical trials are discussed.

In the case of ranolazine, data suggest benefit in the treatment of stable angina pectoris, particularly with sustained release formulations. Trimetazidine appears to have similar physiologic effects to ranolazine, and it is effective as monotherapy and as additive therapy in patients with chronic ischemic heart disease. DCA improves acidosis in critically ill patients and, likewise, improves myocardial hemodynamics in those with chronic coronary artery disease and congestive heart failure; however, its metabolism is variable and clinical data on its use in chronic ischemic heart disease are limited. GIK solutions have been shown to be beneficial in animal and human models of ischemia and acute myocardial infarction, and they offer an inexpensive means by which to improve the oxidation of glucose in the heart. Lastly, a large body of literature suggests a benefit with $L$-carnitine in a number of cardiovascular illnesses, including ischemic heart disease. Clinical trial data in acute myocardial infarction are promising and have prompted the initiation of a large-scale mortality trial.

Traditionally, the management of myocardial ischemia has revolved around the modification of myocardial oxygen supply and demand. Specifically, improving coronary blood flow and alteration of the determinants of oxygen demand, such as blood pressure and heart rate, have been used to improve the clinical manifestations of transient ischemia. This involves the use of drugs that, by design, have systemic as well as cardiac hemodynamic effects. Patient intolerance of these effects often limits the amount of therapy that can be administered, and its effectiveness. Moreover, some patients have such limited coronary blood supply that revascularization and hemodynamic agents are simply not enough. This has led to the investigation of an alternative approach to the management of myocardial ischemia, using metabolically active drugs. 
Metabolically active agents are aimed at modifying myocardial oxygen availability in ways that are independent of systemic hemodynamics and coronary flow. The fundamental goal of this type of therapy is to increase the oxidation of pyruvate formed from glucose, glycogen, and lactate, and to decrease the use of free fatty acids (FFA) as myocardial fuel sources. This article reviews the rationale for and progress in the development of several agents effective at modifying myocardial metabolism in myocardial ischemia.

\section{Myocardial Energy Metabolism}

It is necessary in any review of drugs that influence myocardial metabolism to provide a brief discussion of normal myocardial energy metabolism. The present discussion is not meant to be all inclusive; rather, it is intended to provide a simple framework for the therapeutic implications that follow. For those interested, more detailed accounts are available.[1]

Cardiac contraction and relaxation, both crucial to proper pump function, are both processes that require energy. As in all cells, this energy is derived from the breakdown of adenosine triphosphate (ATP) to adenosine diphosphate (ADP). ADP is reconverted to ATP through a number of pathways, using various fuels. To meet its needs, the heart has the ability to select from a number of different energy-producing substrates. Myocardial energy is mainly derived from glucose and FFA, but under resting conditions, the predominant fuel are long-chain FFA. Oxidation of these fatty acids provides reducing equivalents and a substrate for the various phases of intracellular respiration in the form of acetyl coenzyme A. The terminal phase of the respiratory cycle results in the formation of ATP. Combustion of a typical long-chain fatty acid molecule, such as palmitate, results in the formation of 2.83 moles of ATP for each atom of oxygen. Combustion of 1 mole of glucose results in the formation of 3.17 moles of ATP for each atom of oxygen. The oxidation of glucose is therefore $11 \%$ more efficient than the oxidation of FFA. Under resting conditions, when oxygen is plentiful, this inefficiency is not important to overall myocardial function.

Glucose metabolism consists of 2 main components: glycolysis and glucose oxidation. Glycolysis, an anaerobic process, produces ATP directly, but this accounts for only a small part of overall ATP supply, with the bulk coming from oxidative phosphorylation. Lactate and pyruvate, also myocardial fuels, are by-products of glycolysis. Glucose oxidation occurs through the pyruvate dehydrogenase complex, an intramitochondrial enzyme complex that is extremely important for controlling the rate of the aerobic metabolism of glucose, pyruvate, and lactate. When pyruvate dehydrogenase activity is high, glucose oxidation is stimulated. When it is low, fatty acid oxidation is favored. Therefore, the pyruvate dehydrogenase enzyme complex is extremely important in the selection of the myocardial fuel. Eventually, this aerobic process leads to the formation of ATP through the tricarboxylic acid cycle and the respiratory chain (fig. 1).

During ischemia and reperfusion, FFA levels increase and become even more prominent as energy sources. This is believed to contribute to myocardial cell damage. By whatever mechanism this occurs, and it remains controversial, myocardial oxygen consumption is increased with fatty acid metabolism, thus making a reduction in blood flow less well tolerated. This compounds the problem of limited coronary flow in such conditions. Increasing glucose oxidation during these periods may result in increased efficiency.

It should be apparent that for any treatment aimed at shifting myocardial metabolism from one fuel to another, coronary blood supply should be sufficient to support some oxidative metabolism. Therefore, in conditions where complete or near complete anoxia is present, such as in myocardial infarction where there is no reperfusion after complete occlusion, treatment aimed at shifting from FFA to glucose metabolism would be less likely to be successful.

\section{Available Metabolic Agents}

\section{1 Ranolazine}

Ranolazine, a piperazine derivative (fig. 2), is a novel agent whose effects have recently been investigated. ${ }^{[2]}$ Immediate and sustained release oral preparations of ranolazine have been clinically evaluated. The immediate release formulation is rapidly absorbed following oral administration, with peak plasma concentrations attained 1 hour after administration, and the elimination half-life $(\mathrm{t} t / 2)$ is 1.5 hours. Peak plasma ranolazine concentrations are attained 2.5 to 4 hours after oral administration of the sustained release preparation. Oral bioavailability appears to be in the 30 to $55 \%$ range. Metabolism is extensive with up to 14 routes of elimination having been identified. ${ }^{[3]}$

There are several potential mechanisms by which ranolazine exerts its therapeutic effect, but the reduction in fatty acid oxidation and stimulation of glucose oxidation seem to be the primary mechanisms of action. Using a peripheral muscle model, McCormack et al. ${ }^{[4]}$ showed a significant increase in glucose utilization for ATP production with ranolazine. In an isolated normoxic rat heart model, Clarke et al. ${ }^{[5]}$ demonstrated 


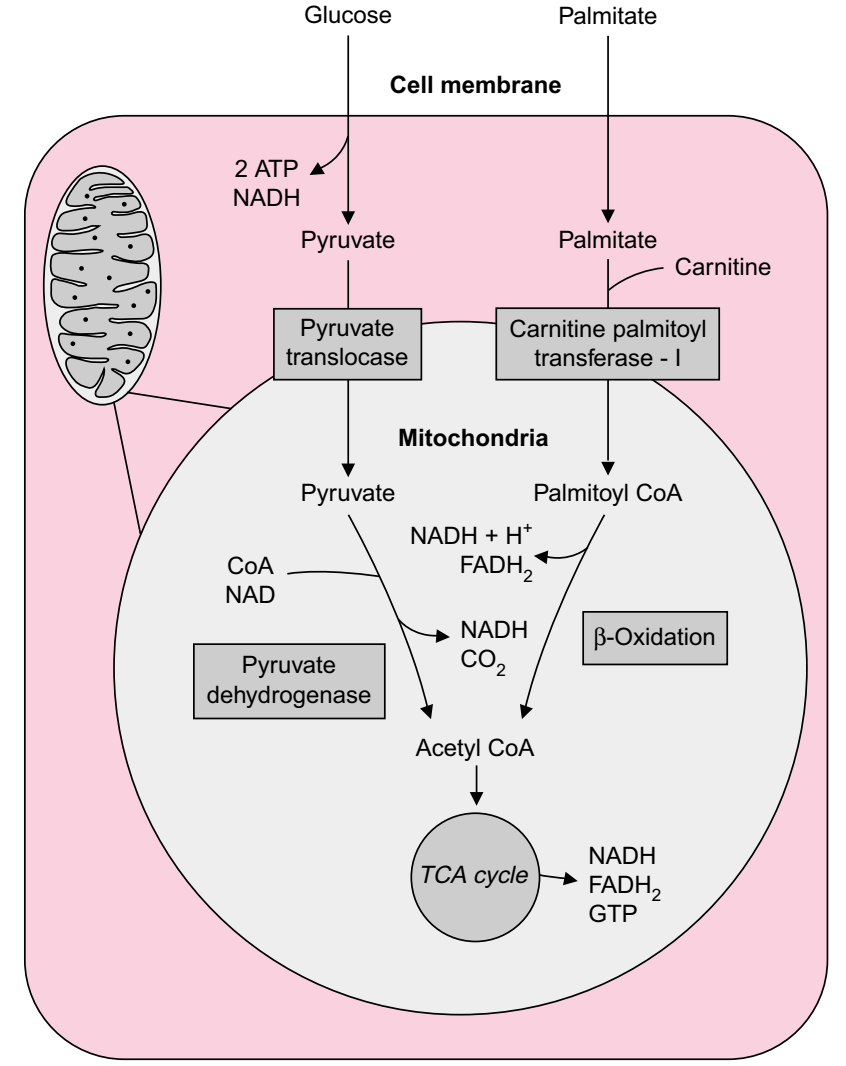

Fig. 1. Myocardial substrate metabolism, showing the interrelationships between carbohydrate and fatty acid metabolism. Acetyl $\mathrm{CoA}=$ acetyl coenzyme A; $\mathbf{A T P}=$ adenosine triphosphate; CPT-1 = carnitine palmitoyl transferase 1 ; $\mathrm{FADH}_{2}$ = flavin adenine dinucleotide (reduced form); GTP = guanosine triphosphate; $\mathbf{N A D H}=$ nicotinamide adenine dinucleotide (reduced form); TCA = tricarboxylic acid.

that ranolazine indirectly activates pyruvate dehydrogenase by inhibiting the $\beta$-oxidation of fatty acids.

In a model also including graded ischemia, McCormack et al. ${ }^{[6]}$ again showed that ranolazine increased glucose oxidation in all of the conditions tested. Additionally, although it did not affect contractile parameters at baseline, ranolazine contributed positively to hemodynamic recovery during ischemiareperfusion, especially when given prior to ischemia. ${ }^{[6]}$ In a baboon preparation of ischemia-reperfusion, Allely and Alps ${ }^{[7]}$ showed a protective effect of pretreatment with ranolazine on myocardial enzyme release after reperfusion. In reperfusion experiments in the rabbit heart, Gralinski et al.$^{[8]}$ also showed significant cardioprotective effects, such as a decrease in histologic markers of injury and inhibition of the decrease in tissue ATP levels noted in the control preparation. However, in conditions of severe ischemia, ranolazine may not be as beneficial. In a longer occlusion-reperfusion study using 90 minutes of occlusion and 18 hours of reperfusion in a dog model, Black et al. ${ }^{[9]}$ failed to show a beneficial effect of ranolazine on measures of injury. This is consistent with the idea that when myocardial blood supply is severely limited, metabolically active agents are less likely to be effective.

Results of studies in animal models have also been mixed regarding the effect of ranolazine on ventricular performance in states of chronic ventricular dysfunction. In a rat chronic myocardial infarction model, Aaker et al. ${ }^{[10]}$ found that long term administration of ranolazine decreased exercise capacity compared with placebo. Interestingly, this was true in the sham-treated animals as well. The reason for this is not clear. In a study looking more specifically at heart failure, Sabbah et al. ${ }^{[11]}$ studied the effect of ranolazine on parameters of left ventricular function in a dog chronic heart failure model. They gave the drug as an intravenous infusion $(0.5 \mathrm{mg} / \mathrm{kg}$ bolus followed by a continuous infusion of $1.0 \mathrm{mg} / \mathrm{kg} / \mathrm{h}$ ). There were no significant changes in heart rate or aortic pressure, but left ventricular ejection fraction, left ventricular end-diastolic volume and pressure, stroke volume and peak positive and negative rate of change of left ventricular pressure all showed significant improvement with ranolazine. Whether these differences were due to the experimental preparation, the dose of ranolazine, or some other factor is not clear and this warrants further investigation.

A number of clinical trials in patients with reversible myocardial ischemia have been performed. Jain et al. ${ }^{[12]}$ reported data from a small series of 14 patients with chronic angina pectoris. After a 2-week placebo period, patients were given either ranolazine 30 or $60 \mathrm{mg}$ orally 3 times daily for 2 weeks. After each administration period, treadmill exercise testing was performed to assess the response at 1.5 and 7 hours postadministration. After 2 weeks of treatment with ranolazine $30 \mathrm{mg}$, mean exercise time increased from $6.9 \pm 0.7$ to $8.2 \pm$ 0.9 minutes $(\mathrm{p}<0.002)$ during the 1.5 -hour postadministration exercise test. Likewise, at the 7-hour test, the mean time was increased; $6.5 \pm 0.6$ to $8.2 \pm 0.8$ minutes $(\mathrm{p}<0.002)$. The $60 \mathrm{mg}$ dose did not significantly further increase exercise time at either time period. The time to onset of angina pectoris also improved significantly with both dosages and during both<smiles>COc1ccccc1OCC(O)CN1CCN(CC(=O)Nc2c(C)cccc2C)CC1</smiles>

Fig. 2. Ranolazine: ( \pm )- $N$-(2,6-dimethyl-phenyl)-4-[2-hydroxy-3-(2-methoxyphenoxy)-propyl]-1-piperazine acetamide. * Denotes the chiral center. 
Table I. Clinical trials of metabolically active drugs in ischemic heart disease

\begin{tabular}{|c|c|c|c|c|c|}
\hline Drug & $\begin{array}{l}\text { Study } \\
\text { design }\end{array}$ & $\begin{array}{l}\text { No. of } \\
\text { pts }\end{array}$ & $\begin{array}{l}\text { Adjunctive } \\
\text { therapy }\end{array}$ & $\begin{array}{l}\text { Study } \\
\text { duration }\end{array}$ & Dose \\
\hline \multicolumn{6}{|c|}{ Ranolazine (RAN) } \\
\hline $\begin{array}{l}\text { Thadani } \\
\text { et al. }{ }^{[13]}\end{array}$ & $\begin{array}{l}\mathrm{r}, \mathrm{db} \\
\mathrm{mc}, \mathrm{pc}\end{array}$ & 319 & Withdrawn & $4 \mathrm{wk}$ & RAN $(30,60$, or $120 \mathrm{mg}$ po tid) or PL \\
\hline $\begin{array}{l}\text { Cocco } \\
\text { et al. }{ }^{[14]}\end{array}$ & $\begin{array}{l}\mathrm{r}, \mathrm{db} \\
\mathrm{mc}, \mathrm{pc} \\
\mathrm{co}\end{array}$ & 104 & $\beta$-Blockers, diltiazem & so & RAN $(10,60,120,240 \mathrm{mg}$ single dose) or PL \\
\hline $\begin{array}{l}\text { Pepine \& } \\
\text { Wolff }{ }^{[15]}\end{array}$ & $\begin{array}{l}\mathrm{r}, \mathrm{db} \\
\mathrm{mc}, \mathrm{pc} \\
\mathrm{co}\end{array}$ & 312 & $\begin{array}{l}\text { Adjusted to shorten } \\
\text { onset of angina } \\
\text { pectoris by } \geq 1 \mathrm{~min}\end{array}$ & $5 w k$ & RAN (267mg tid, $400 \mathrm{mg}$ tid, $400 \mathrm{mg}$ bid) or PL \\
\hline Wolff ${ }^{[16]}$ & $\begin{array}{l}\mathrm{r}, \mathrm{db} \\
\mathrm{mc}, \mathrm{pc} \\
\mathrm{co}\end{array}$ & 175 & Withdrawn & $7-9 w k$ & $\begin{array}{l}\text { RAN (sustained release formulation, } 500 \text {, or } \\
1500 \mathrm{mg} \text { bid) }\end{array}$ \\
\hline
\end{tabular}

Outcomes

No change in total exercise duration, time to $1 \mathrm{~mm} \mathrm{ST}$ segment depression, or time to onset of angina pectoris No change in exercise variables with RAN 10,60, or $120 \mathrm{mg}$; significant improvement in exercise duration, time to onset of angina pectoris, and time to $1 \mathrm{~mm} \mathrm{ST}$ segment depression with RAN $240 \mathrm{mg}$

Improved time to $1 \mathrm{~mm}$ ST segment depression for the combined treatment groups; other variables improved only at peak plasma concentrations

Improved exercise duration, time to onset of angina pectoris, and time to $1 \mathrm{~mm}$ ST segment depression in all RAN-treated groups at both peak and trough plasma concentrations

Trimetazidine (TRI)

\begin{tabular}{|c|c|c|c|c|c|}
\hline $\begin{array}{l}\text { Kober } \\
\text { et al. }{ }^{[17]}\end{array}$ & $\mathrm{r}, \mathrm{db}, \mathrm{pc}$ & 20 & $\begin{array}{l}\beta \text {-Blockers, calcium } \\
\text { blockers withdrawn }\end{array}$ & so & $\begin{array}{l}\text { TRI (6mg intracoronary } \times 1 \text { single } \\
\text { administration) }\end{array}$ \\
\hline $\begin{array}{l}\text { Detry } \\
\text { et al. }{ }^{[18]}\end{array}$ & $\begin{array}{l}\mathrm{r}, \mathrm{db} \\
\mathrm{pg}, \mathrm{mc}\end{array}$ & 149 & $\begin{array}{l}\text { Baseline antianginal } \\
\text { therapy withdrawn }\end{array}$ & $3 \mathrm{mo}$ & TRI (20mg tid) or propranolol $40 \mathrm{mg}$ tid po \\
\hline $\begin{array}{l}\text { Szwed } \\
\text { et al. }{ }^{[19]}\end{array}$ & $\begin{array}{l}\mathrm{nr}, \mathrm{mc}, \\
\mathrm{pg}\end{array}$ & 700 & $\begin{array}{l}\text { Long-acting } \\
\text { nitrates, } \beta \text {-blockers, } \\
\text { calcium blockers }\end{array}$ & $4 w k$ & TRI 20mg po tid \\
\hline $\begin{array}{l}\text { Levy et } \\
\text { al. }^{[20]}\end{array}$ & $\begin{array}{l}\mathrm{r}, \mathrm{mc}, \\
\mathrm{pc}, \mathrm{db}\end{array}$ & 67 & $\begin{array}{l}\text { Diltiazem 60mg po } \\
\text { tid }\end{array}$ & $6 w k$ & TRI 20mg po tid \\
\hline \multicolumn{6}{|c|}{ Dichloroacetate (DCA) } \\
\hline $\begin{array}{l}\text { Stacpoole } \\
\text { et al. }{ }^{[21]}\end{array}$ & $\mathrm{nr}$, obs & 13 & & $20 \mathrm{~h}$ & DCA $35-50 \mathrm{mg} / \mathrm{kg}$ IV over $30 \mathrm{~min}$ \\
\hline $\begin{array}{l}\text { Stacpoole } \\
\text { et al. }{ }^{[22]}\end{array}$ & $\mathrm{r}, \mathrm{pc}, \mathrm{mc}$ & 252 & & $80 \mathrm{~h}$ & DCA 50 mg/kg IV over 30 min \\
\hline $\begin{array}{l}\text { Wargovich } \\
\text { et al. }{ }^{[23]}\end{array}$ & $\mathrm{nr}$, obs & 9 & & so & DCA (mean dose 35 mg/kg IV over $15 \mathrm{~min}$ ) \\
\hline $\begin{array}{l}\text { Bersin } \\
\text { et al. }{ }^{[24]}\end{array}$ & $\mathrm{nr}$, obs & 10 & Dobutamine & $2 \mathrm{~h}$ & $\begin{array}{l}\text { DCA }(50 \mathrm{mg} / \mathrm{kg} \text { IV over } 30 \mathrm{~min}) \text {, dobutamine } \\
(5-12.5 \mu \mathrm{g} / \mathrm{kg} / \mathrm{min})\end{array}$ \\
\hline
\end{tabular}

Single dose of TRI reduced ischemic-related ST segment abnormalities during LAD angioplasty TRI effect equivalent to propranolol in time to onset of angina pectoris, maximum ST segment depression, and time to $1 \mathrm{~mm}$ ST segment depression

Decreased number of anginal episodes, decreased use of nitrates, and improved time to $1 \mathrm{~mm} \mathrm{ST}$ segment depression with TRI Improved ischemic threshold with TRI compared with controls

DCA reduced arterial lactate levels, improved arterial $\mathrm{pH}$, increased systolic blood pressure, and increased cardiac output in patients with acidosis

DCA reduced arterial lactate levels and raised arterial $\mathrm{pH}$ but had no effect on mortality or hemodynamics in patients with acidosis

DCA increased LV stroke volume, decreased systemic vascular resistance and improved myocardial efficiency in patients with coronary artery disease Improved LV mechanical efficiency noted with DCA and with dobutamine, with opposite effects on lactate metabolism seen with the 2 drugs

Glucose-insulin-potassium (GIK)

\begin{tabular}{|c|c|c|c|c|c|}
\hline $\begin{array}{l}\text { Rogers } \\
\text { et al. }{ }^{[25]}\end{array}$ & $\mathrm{nr}$, obs & $\begin{array}{l}70(64 \text { pts } \\
\text { served as }\end{array}$ & $\begin{array}{l}\text { 'Conventional' } \\
\text { post-Ml care }\end{array}$ & $48 \mathrm{~h}$ & $\begin{array}{l}3 \% \text { glucose with } 50 \mathrm{U} / \mathrm{L} \text { insulin, } 80 \mathrm{mmol} / \mathrm{L} \\
\mathrm{KCl} \text {, mean infusion rate } 1.26 \mathrm{ml} / \mathrm{kg} / \mathrm{L}\end{array}$ \\
\hline
\end{tabular}

Dramatic fall in plasma FFA during infusion, overall $47 \%$ mortality reduction compared with historical controls controls)

Malmberg r, mc,pg $620 \quad$ Thrombolytic

$5 \%$ glucose with $160 \mathrm{U} / \mathrm{L}$ insulin at $30 \mathrm{ml} / \mathrm{h}$

Mortality reduced $29 \%$ in treatment group, effects minimum 24 hours, then subcutaneous insulin more pronounced in non-insulin-dependent patients for $\geq 3 \mathrm{mo}$ with diabetes

High dose GIK: $25 \%$ glucose, $50 \mathrm{U} / \mathrm{L}$ insulin, $80 \mathrm{mmol} / \mathrm{L} \mathrm{KCl}$ at $1.5 \mathrm{ml} / \mathrm{kg} / \mathrm{h}$ over $24 \mathrm{~h}$ Significant mortality reduction in the high dose GIK Low dose GIK: $10 \%$ glucose, $20 \mathrm{U} / \mathrm{L}$ insulin, $40 \mathrm{mmol} / \mathrm{L} \mathrm{KCl}$ at $1.0 \mathrm{ml} / \mathrm{kg} / \mathrm{h}$ over $24 \mathrm{~h}$ patients receiving reperfusion therapy

\section{L-Carnitine}

Singh et $r, d b, p c \quad 101$

al. ${ }^{[28]}$

Thrombolytic therapy $(62 \%)$

lliceto $\quad r, d b, \quad 472$

et al. ${ }^{[29] \quad p c, m c}$

Colonna \& $r, \mathrm{db}, 4000$

lliceto $^{[30] \quad \mathrm{pc}, \mathrm{mc}}$

\author{
Usual post-MI care \\ Thrombolytic \\ therapy $(80 \%)$ \\ Ongoing

\section{8 days $\quad$ L-Carnitine $660 \mathrm{mg}$ po tid} \\ $12 \mathrm{mo}$ \\ $6 \mathrm{mo}$ \\ L-Carnitine $9 \mathrm{~g}$ /day continuous IV infusion $\times 5$ \\ days then $2 \mathrm{~g}$ po tid $\times 12 \mathrm{mo}$ \\ Ongoing
}

Reduced CK rise, extent of angina pectoris, arrhythmias, and NYHA classification with $L$-carnitine

Reduced LV volume measurements noted at 3,6, and $12 \mathrm{mo}$ with $L$-carnitine, trend toward reduced mortality CEDIM-2 trial ongoing, primary end-point combined incidence of death or chronic heart failure

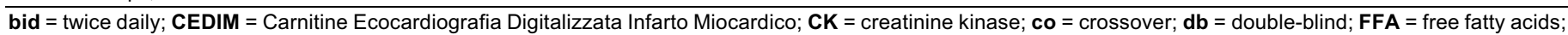

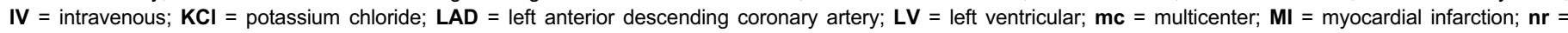

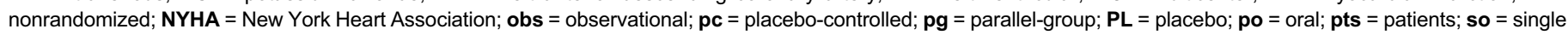
observation; tid $=3$ times daily. 
postadministration exercise tests. All of these effects occurred without changes in blood pressure or heart rate, either at rest or at peak exercise.

Not all clinical trials of ranolazine have been positive. Thadani et al. ${ }^{[13]}$ reported results from a large study in which 318 patients with chronic stable angina pectoris were randomized to receive either ranolazine $(30,60$, or $120 \mathrm{mg} 3$ times daily) or placebo after a single-blind placebo period of up to 18 days (table I). ${ }^{[13]}$ The ischemic measures used were exercise test parameters, anginal episodes per week, and number of ischemic episodes on 48-hour ambulatory electrocardiographic monitoring. They evaluated patients at peak drug plasma concentration and at 8 hours postadministration. All of the patients remained stable during the placebo period. After 4 weeks' double-blind therapy, these investigators found improvements in most parameters compared with baseline, but no differences were noted between any of the 3 dosages of ranolazine and placebo. It is not clear whether a higher dosage of ranolazine might have been effective or whether ranolazine would have been more effective in more symptomatic patients.

Ranolazine has also been tested as additive therapy in patients with ischemic heart disease. Cocco et al. ${ }^{[14]}$ reported on a series of 104 patients who had persistent angina pectoris and ST segment depression on exercise testing despite treatment with either diltiazem or a $\beta$-adrenoceptor antagonist ( $\beta$-blocker). Four single doses of ranolazine were tested: $10,60,120$, and $240 \mathrm{mg}$. No differences were noted in exercise duration or time to onset of angina pectoris with the 3 lowest doses, but at the $240 \mathrm{mg}$ dose, there was a significant increase in time to $1 \mathrm{~mm}$ ST segment depression $(p=0.03)$ and time to onset of angina pectoris $(\mathrm{p}=0.01)$. This occurred without a significant change in the rate-pressure product at maximum exercise. In all, time to onset of angina pectoris improved with the addition of ranolazine to standard regimen in $72 \%$ of patients. Interestingly, the patients receiving diltiazem had significant elevations in mean plasma ranolazine concentrations compared with the $\beta$-blocker group, indicating delayed metabolism of the drug with concurrent use of diltiazem.

Pepine and Wolff, ${ }^{[15]}$ for the Ranolazine Study Group, recently reported data from 312 patients studied in a complex protocol. The angina pectoris in these patients had been stabilized with long term therapy. After exercise testing, antianginal agents were withdrawn until the patient's exercise time was reduced by at least 1 minute. At that point, patients were randomized to receive 1 of 3 dosages of ranolazine, $267 \mathrm{mg} 3$ times daily, 400mg twice daily, or $400 \mathrm{mg} 3$ times daily, or placebo. They observed that exercise test parameters improved significantly at peak ranolazine plasma concentra- tions without increases in the double product. This is consistent with the method of action of ranolazine. At trough concentrations, however, the effects were less, with only time to $1 \mathrm{~mm}$ ST segment depression remaining significantly different. The authors concluded that the preparation used, immediate release ranolazine, was effective but limited in its ability to provide protection against ischemia for the entire duration of treatment.

Ranolazine appears to be well tolerated and participants taking the drug in the described clinical trials did not experience serious adverse effects. The most common adverse effects reported have been dizziness, headache, and fatigue, although drug withdrawals for these effects have been rare $(\leq 6 \%$ of recipients) and similar to those with placebo (table II). In the study by Pepine et al., ${ }^{[15]}$ the numbers of patients with any adverse effect were similar between ranolazine and placebo (approximately 25\%), and only minor gastrointestinal adverse effects occurred more often with ranolazine than with placebo ( 6.6 to $10.7 \%$ vs $3.2 \%$ ). The drug is effective in relieving myocardial ischemia, but the dosage needed is higher than that initially tested, and the immediate release formulation tested is suboptimal for providing long lasting therapeutic effect.

In the most recently reported Monotherapy Assessment of Ranolazine in Stable Angina (MARISA) trial, data from 175 patients randomized to 3 different dosages $(500,1000$, and $1500 \mathrm{mg}$ twice daily) of ranolazine or placebo were reported.[16] All other antianginal drugs were withdrawn. In an effort to counteract some of the problems with earlier forms of administration (specifically the lack of prolonged response), a newer sustained release formulation was used that allowed for twice daily administration. As in other studies, no effect on resting blood pressure or heart rate was noted with ranolazine. The exercise test variables of exercise duration, time to onset of angina pectoris, and time to $1 \mathrm{~mm} \mathrm{ST} \mathrm{segment} \mathrm{depression} \mathrm{were}$ all improved with ranolazine compared with placebo (all $\mathrm{p} \leq$ 0.005). These results were observed at both peak and trough plasma concentrations of ranolazine in all dosage groups. Thus, while ranolazine has been shown to be well tolerated

Table II. Common adverse effects of metabolically active drugs used in the management of ischemic heart disease

\begin{tabular}{ll}
\hline Ranolazine & Gastrointestinal upset, fatigue, headache, dizziness \\
Trimetazidine & $\begin{array}{l}\text { Gastrointestinal upset, myalgia, fatigue } \\
\text { Dichloroacetate }\end{array}$ \\
$\begin{array}{l}\text { neuropathy } \\
\text { Glucose-insulin- } \\
\text { potassium }\end{array}$ & $\begin{array}{l}\text { Phlebitis, hyperkalemia, hyper- and hypoglycemia, } \\
\text { pulmonary congestion, pulmonary infiltrate }\end{array}$ \\
L-Carnitine & $\begin{array}{l}\text { Body odor, gastrointestinal upset, visual blurring, } \\
\text { headache, pyrosis }\end{array}$ \\
\hline
\end{tabular}


and beneficial in selective animal and human trials of cardiac ischemia, larger clinical trials utilizing the long-acting preparation are still needed to conclusively establish its effectiveness.

\subsection{Trimetazidine}

Trimetazidine is a 1-[2,3,4-trimethoxybenzyl] piperazine dihydrochloride salt that has anti-ischemic activity reported in the absence of an effect on myocardial oxygen consumption or blood supply. ${ }^{[31]}$ In its physiological actions, trimetazidine resembles ranolazine in a number of aspects. Details of the structure, function, and clinical utility of trimetazidine in myocardial ischemia has recently been reviewed. ${ }^{[32]}$ Trimetazidine appears to be rapidly absorbed following oral administration, with mean a peak plasma concentration noted 1.8 hours after a $20 \mathrm{mg}$ oral dose. ${ }^{[33]}$ The bioavailability of a $40 \mathrm{mg}$ oral dose of trimetazidine is $88 \%$ relative to that of intravenous administration. ${ }^{[34]}$ Plasma protein binding is limited (about $16 \%$ ) and elimination appears to be primarily urinary, with a $t \frac{1}{2}$ of 6 hours after a $20 \mathrm{mg}$ dose. ${ }^{[33]}$

As with ranolazine, the specific mechanism of action of trimetazidine is unknown; however, a variety of studies have demonstrated anti-ischemic activity via a direct action on the myocardial cell. Trimetazidine appears to limit ischemiarelated acidosis, calcium overload, and oxygen free radical damage, ${ }^{[35-37]}$ and may furthermore act by preserving intracellular levels of phosphocreatine and ATP. ${ }^{[35]}$ Kober et al. ${ }^{[17]}$ investigated the cytoprotective action of trimetazidine in 20 patients undergoing balloon angioplasty of the left anterior descending coronary artery (table I). Patients underwent 3 successive balloon inflations with trimetazidine (6mg intracoronary bolus) or placebo given in a blinded manner prior to the third balloon inflation. Compared with placebo, there was a significant improvement in maximum ST segment shift, peak T wave amplitude, and area under the ST-T wave curve plotted as a function of time during balloon inflation ( $\mathrm{p}<0.05$ for each parameter). Trimetazidine had no effect on systemic hemodynamics or intracoronary occlusion pressure, suggesting a direct cytoprotective effect of the drug.

Trimetazidine has been shown to be comparable to standard therapy with propranolol in the treatment of ischemic heart disease. The Trimetazidine European Multicenter Study (TEMS) included 149 male patients with stable angina pectoris and documented coronary artery disease based on a history of myocardial infarction or abnormal coronary angiogram. ${ }^{[18]}$ Patients were randomized to receive either trimetazidine $20 \mathrm{mg}$ or propranolol $40 \mathrm{mg}$ orally 3 times daily for 3 months. The duration of symptom-free exercise, time to $1 \mathrm{~mm}$ ST segment depression, maximum ST segment depression, and time to onset of angina pectoris were similar in both groups.

Szwed et al. ${ }^{[19]}$ studied the addition of trimetazidine to background therapy (long-acting nitrate, $\beta$-blocker, calcium channel antagonist) in 700 nonrandomized patients with chronic ischemic heart disease. After 4 weeks of additive therapy with trimetazidine, there was a significant decrease in the number of anginal episodes (3.66 to 2.47/week, $\mathrm{p}<0.01$ ) and the use of supplemental nitrates (2.94 to 1.8 units/week, $\mathrm{p}<$ 0.01 ), and a significant increase in the time to $1 \mathrm{~mm}$ ST segment depression on exercise testing (338 to 390 seconds, $\mathrm{p}<$ $0.01)$.

The combination of trimetazidine and diltiazem was studied by the Group of South of France Investigators ${ }^{[20]}$ in 67 patients with stable angina pectoris and a positive exercise test. Included patients received either trimetazidine $20 \mathrm{mg} 3$ times daily $(\mathrm{n}=32)$ or placebo $(\mathrm{n}=35)$ in combination with diltiazem $60 \mathrm{mg} 3$ times daily for 6 months. At end-point, the addition of trimetazidine had prolonged the ischemic threshold on exercise testing from 373 to 534 seconds $(\mathrm{p}<0.001)$ while no statistically significant benefit was observed in the group receiving placebo and diltiazem (479 to 521 seconds). Trimetazidine, therefore, appears to have similar efficacy in direct comparison to standard anti-ischemic therapy, and may provide additional benefit when added to conventional therapy.

In smaller trials, trimetazidine has been shown to reduce ischemia-related reperfusion injury during cardiac surgery, ${ }^{[38]}$ and to improve left ventricular ejection fraction and reduce left ventricular volume in patients with ischemic cardiomyopathy. ${ }^{[39]}$ In a recent provocative trial of 34 patients with cardiac syndrome $\mathrm{X}$ (defined as the presence of angina pectoris with a positive exercise test, yet with a normal coronary angiogram), Rogacka et al. ${ }^{[40]}$ demonstrated an improvement in the incidence of effort angina pectoris (76 to 38\%) after 6 months' treatment with oral trimetazidine $20 \mathrm{mg} 3$ times daily. Significant improvement in exercise duration was reported after 1 month of therapy ( 563 to 652 seconds, $p=0.005$ ). Thus, trimetazidine may have a role in correcting microvascular ischemia, which appears to be the central feature of cardiac syndrome X. Tolerability with trimetazidine appears to be high, approximating that of placebo when given as adjunctive therapy with other antianginals. In monotherapy comparison trials, oral trimetazidine appears to be better tolerated than either nifedipine ${ }^{[41]}$ or propranolol. ${ }^{[18]}$ Dyspepsia has been the most commonly reported adverse effect, but its overall incidence is low (table II). ${ }^{[32]}$ 


\subsection{Dichloroacetate}

Another metabolic agent evaluated in myocardial ischemia is dichloroacetate (DCA). DCA has been known as a topical keratolytic/astringent compound and as a metabolite of certain drugs, such as chloramphenicol[ ${ }^{[42]}$ and flurane anesthetic agents, ${ }^{[43]}$ for a number of years. ${ }^{[44]}$ The sodium salt of DCA has more recently been reported to stimulate pyruvate dehydrogenase (PDH) activity by inhibiting pyruvate dehydrogenase kinase. PDH catalyses the conversion of pyruvate to acetyl coenzyme A within the mitochondria, thereby increasing intracellular uptake of pyruvate and reducing blood glucose, alanine, and lactate levels. Most of the clinical data on DCA have been gathered from its use as an intravenous infusion, which has limited its availability to the hospital setting. Pharmacokinetic studies have shown that DCA has a high bioavailability after oral administration, and that the initial dosage significantly influences the metabolism of subsequent dosages. In a study in healthy volunteers, Curry et al. ${ }^{[44]}$ found that this effect could last as long as 3 months with either oral or intravenous administration, and that the effect varied widely among individuals. The initial $\mathrm{t}_{1} / 2$ increased from 1.58 to 3.64 hours and 9.9 hours for the second and subsequent doses of the drug. Clearance of DCA appears to occur predominantly by conversion to an oxalate in plasma, with a lesser degree of renal elimination. ${ }^{[44]}$

DCA has a variety of physiologic effects, all being potentially beneficial to the ischemic heart. It acts by stimulating PDH activity which favors glucose oxidation. It also probably inhibits fatty acid uptake by myocardial cells, and thus promotes glucose uptake. By virtue of its ability to increase lactate metabolism, DCA may increase intracellular $\mathrm{pH}$, limiting the acidosis that occurs during ischemia. By whichever of these mechanisms the benefit occurs, it is clear that, at least in the short term, DCA appears to improve a variety of hemodynamic parameters without detrimental effects. Using various animal models with both isolated and in vivo preparations, this agent has been shown to improve functional recovery after ischemia, improve mechanical efficiency, increase contractile force, and decrease measures of ischemia. ${ }^{[45-47]}$

Since DCA reduces serum lactate level, it has been investigated as a potential therapeutic agent in critically ill patients with lactic acidosis. Stacpoole et al. ${ }^{[21]}$ administered DCA to 13 patients with significant lactic acidosis (lactate level $\geq 5$ $\mathrm{mmol} / \mathrm{L}$ ) [table I]. ${ }^{[21]}$ With treatment, they found a decreased serum lactate level in 7 patients, with improvement in their serum pH. In 6 of the 7 patients, the acidemia resolved. Four of the 13 patients had improved cardiac output and 10 had increased systolic blood pressure. No serious drug-related adverse events were noted. However, 12 of the 13 patients died despite therapy with DCA.

In a subsequent larger, multicenter trial, these and other investigators randomized 252 patients with lactic acidosis to receive either DCA or placebo in addition to conventional therapy. ${ }^{[22]}$ Again, the entry criteria included a blood lactate level of $\geq 5 \mathrm{mmol} / \mathrm{L}$ and clinical evidence of acidosis. The vast majority of patients were on a ventilator and were receiving inotropic agents. In $66 \%$ of the patients, arterial lactate levels decreased by $\geq 20 \%$, and arterial $\mathrm{pH}$ also improved significantly with DCA compared with placebo. As in the smaller study, ${ }^{[21]}$ this improvement did not lead to increased survival, with only 12 and $17 \%$ of DCA and placebo recipients, respectively, surviving to discharge. These patients were obviously very ill, as indicated by their limited survival, but these data suggest that treatment aimed solely at improving the acid-base balance as an adjunct to treatment aimed at the underlying cause of deterioration may not be that important in improving outcome.

To examine the hemodynamic effects of DCA in individuals without acidosis, Ludvik et al. ${ }^{[48]}$ administered the drug to 10 healthy volunteers. They found significant $(\mathrm{p}<0.05)$ improvements in the cardiac index $(2.3 \pm 0.03$ to $2.7 \pm 0.1$ $\mathrm{L} / \mathrm{min} / \mathrm{m}^{2}$ ), significant decreases in peripheral resistance ( $2662 \pm 97$ to $2398 \pm 169 \mathrm{dyne} \cdot \mathrm{s} \cdot \mathrm{cm}^{-5}$ ), significant improvements in oxygen availability, and significant decreases in serum lactate level $(1.4 \pm 0.14$ to $0.6 \pm 0.01 \mathrm{mmol} / \mathrm{L})$. Thus, it seems that the interaction of acidosis, underlying disease, and the effects of DCA on hemodynamics is not yet completely understood.

There are few clinical trials using DCA in patients with heart disease. Wargovich et al. ${ }^{[23]}$ reported data from a series of trials evaluating the effects of DCA in patients with ischemic heart disease. Patients with ischemic heart disease undergoing cardiac catheterization were given DCA (mean dose 35 $\mathrm{mg} / \mathrm{kg}$ intravenously over 15 minutes). Systemic and coronary hemodynamic, myocardial lactate extraction, and oxygen consumption measurements were made. Heart rate, blood pressure, left ventricular end-diastolic pressure, coronary sinus flow, maximum rate of change in left ventricular pressure, or myocardial oxygen consumption did not change from pretreatment values after the administration of DCA. Myocardial lactate extraction was unchanged at a lower lactate level. However, left ventricular stroke volume increased and systemic resistance decreased, thereby indicating improved myocardial efficiency.

Bersin et al. ${ }^{[24]}$ evaluated the effects of DCA in patients with congestive heart failure. They measured systemic and 
coronary hemodynamics before and after the administration of DCA $(50 \mathrm{mg} / \mathrm{kg}$ intravenously over 30 minutes) in 10 patients with New York Heart Association class III or IV heart failure (7 with ischemic cardiomyopathy). They found no change in heart rate or right and left heart pressures; however, there was an increase in stroke volume and cardiac index. Myocardial lactate extraction was improved, with very low coronary sinus lactate levels being present at 60 minutes after starting DCA therapy. These data are consistent with an improvement in left ventricular mechanical efficiency related mostly to a decrease in myocardial oxygen consumption. These patients were subsequently given dobutamine after an overnight drug-free period. The cardiac output and stroke volume changes were similar to the peak effects with DCA, but myocardial lactate consumption was significantly decreased with dobutamine compared with DCA. Oxygen consumption increased and mechanical efficiency was unchanged with dobutamine. $\beta$-Adrenoceptor stimulation is associated with decreased glucose and lactate consumption; DCA has the opposite effect. This suggests that the use of these 2 agents would be complementary in improving myocardial performance. While intriguing, this theory has yet to be proven.

While DCA has generally been well tolerated in clinical studies, the most common adverse effects reported have been drowsiness and a sedative-like effect (table II). This effect was noted in each of the 2 non-ventilator-dependent patients receiving DCA in the original lactic acidosis trial of Stacpoole et al. ${ }^{[21]}$ A single report of reversible peripheral neuropathy has also been described ${ }^{[49]}$ Concern over unpredictable elimination has led to doubts regarding the safety of long term administration of DCA, clearly hampering further investigation of DCA in clinical trials and limiting its potential clinical applicability.

\subsection{Glucose-Insulin-Potassium}

The use of glucose-insulin-potassium (GIK) solutions in the setting of myocardial ischemia and infarction has been proposed for nearly 40 years. The rationale for this therapy is that in the presence of insulin glucose will be driven into the myocyte, where it may be made available for glycolysis. Additionally, potassium reuptake via sodium-potassium ATPase is stimulated by insulin and by high plasma levels of potassium, leading to increased intracellular potassium levels and membrane stabilization. The increased availability of substrate noted with glucose/insulin administration results in a small but measurable increase in the amount of ATP produced via glycolysis, and a higher free energy yield from ATP hydrolysis. ${ }^{[50]}$ A further beneficial effect of GIK therapy is the suppression of plasma FFA levels and myocardial FFA uptake, which occurs in the presence of high glucose/insulin levels. ${ }^{[51,52]}$ The presence of glucose and insulin under conditions of ischemia also preserves and restores myocardial glycogen content, an important determinant of myocardial contractile function. Furthermore, the glycolytic generation of ATP improves sodium and calcium homeostasis through membrane stabilizing effects. Increased glycolytic ATP also offers myocardial protection during reperfusion.

In an animal model of evolving myocardial infarction, isolated blood-perfused rabbit hearts underwent 150 minutes of severe low-flow ischemia and reperfusion. ${ }^{[53]}$ The use of a high glucose/insulin substrate was compared with a control substrate and it demonstrated greater pressure generation and preservation of diastolic function compared with the control hearts. In addition, glucose/insulin-treated hearts had greater coronary blood flow, preservation of glycogen stores, and less leakage of creatine kinase compared with control hearts.

The initial clinical use of GIK was reported in 1962 by Sodi-Pallares et al. ${ }^{[54]}$ Its use was based on the rationale that it might improve the arrhythmias and electrocardiographic abnormalities associated with acute myocardial infarction. ${ }^{[54]}$ These authors demonstrated that a solution of GIK (called 'polarizing solution' for its presumed membrane-stabilizing action) shortened the electrocardiographic evolution of acute myocardial infarction, reduced ventricular ectopy, and improved early survival. Throughout the 1960s and 1970s, a number of clinical trials attempted to confirm these findings in patients with acute myocardial infarction. Results of these trials were inconclusive, however, and they suffered from a number of methodological flaws, including small numbers of patients, varying times to initiation of GIK therapy, and different administration regimens of GIK itself.

The most convincing early results were noted with higher concentration GIK solutions. A comprehensive review of the experience with GIK in acute myocardial infarction from a single center described the use of a solution of $30 \%$ glucose $(300 \mathrm{~g} / \mathrm{L}), 50 \mathrm{U} / \mathrm{L}$ regular insulin, and $80 \mathrm{mEq} / \mathrm{L}$ potassium chloride given intravenously to 70 patients at a rate of 1.5 $\mathrm{ml} / \mathrm{kg} / \mathrm{h}$ (table I). ${ }^{[25,55]}$ Known as the 'Rackley' solution, it markedly increased myocardial glucose uptake and decreased both arterial FFA levels and myocardial FFA uptake. Clinical end-points measured in these trials ${ }^{[25,55]}$ with the Rackley solution included improved cardiac function, decreased ventricular arrhythmias, and a trend toward decreased mortality in patients with acute myocardial infarction. 
Fath-Ordoubadi et al. ${ }^{[56]}$ subsequently reported metaanalysis data on 9 clinical trials (1932 patients) of GIK therapy in acute myocardial infarction. Hospital mortality was reduced from $21 \%$ in the placebo group to $16.1 \%$ in the GIK group $(\mathrm{p}=0.004)$, a proportional mortality reduction of $28 \%$. In the combined patient subset, 49 lives were saved per 1000 patients treated with GIK. Of the 4 trials using the Rackley (high dose) GIK solution, the proportional mortality reduction was $48 \%$, although statistical significance was not reached because of small sample sizes. While intriguing, this meta-analysis included only 1 trial from the modern thrombolytic era, and that small trial showed no benefit with GIK. Also, while the pooled data were significant, only 1 of the trials included in the metaanalysis showed a significant benefit by itself.[56]

Two more recent trials have been conducted during the era of reperfusion therapy. The Diabetes Mellitus Insulin-Glucose Infusion in Acute Myocardial Infarction (DIGAMI) trial enrolled 620 patients with diabetes mellitus and acute myocardial infarction and randomized them to receive glucose/insulin followed by multidose insulin therapy $(\mathrm{n}=306)$ or to receive standard care $(\mathrm{n}=314){ }^{[26]}$ The glucose/insulin recipients received an infusion of $5 \%$ glucose with insulin $160 \mathrm{U} / \mathrm{L}$ at a rate of $30 \mathrm{ml} / \mathrm{h}$, adjusted to maintain normoglycemia, for a minimum of 24 hours. The infusion was then discontinued after stable normoglycemia was noted, and subcutaneous insulin therapy was begun (before meals and at bedtime, dose titrated to maintain normoglycemia) for a further minimum of 3 months. Half of the total patient population received thrombolytic therapy. A $29 \%$ reduction in relative mortality $(p=0.027)$ was seen at 1 year in the glucose/insulin group compared with the control group, with non-insulin-requiring patients with diabetes exhibiting the most benefit (58\% in-hospital mortality reduction and 52\% 1-year mortality reduction).

The recent Estudios Cardiológicos Latinoamérica (ECLA) study was the largest prospective, randomized trial of GIK ever undertaken. ${ }^{[27]}$ A total of 407 patients with suspected acute myocardial infarction received GIK (high or low dose, $\mathrm{n}=268$ ) or standard therapy. High dose GIK consisted of $25 \%$ glucose, $50 \mathrm{U} / \mathrm{L}$ of insulin, and $80 \mathrm{mmol} / \mathrm{L}$ potassium chloride at an infusion rate of $1.5 \mathrm{ml} / \mathrm{kg} / \mathrm{h}$ over 24 hours. Low dose GIK consisted of $10 \%$ glucose, $20 \mathrm{U} / \mathrm{L}$ of insulin, and $40 \mathrm{mmol} / \mathrm{L}$ of potassium chloride at an infusion rate of $1.0 \mathrm{ml} / \mathrm{kg} / \mathrm{h}$ over 24 hours. Among the patients receiving reperfusion therapy ( 252 out of 407 patients), there was a $66 \%$ reduction in relative in-hospital mortality in patients randomized to receive GIK $(\mathrm{p}=0.008)$. The absolute mortality risk decreased from 15.2 to $5.2 \%$. There was no benefit with the use of GIK in patients not receiving reperfusion therapy. Additionally, among those receiving GIK, benefit was confined to the high dose group only. The limitations of this trial included nonblinded treatment, liberal entry criteria, and an unexpectedly high mortality rate in the control patients receiving reperfusion therapy. Nevertheless, the results in the GIK/reperfusion recipients were impressive.

The theoretical benefits of GIK in ischemia/reperfusion should, likewise, be applicable during cardiac surgery. In a prospective, randomized trial, Lazar et al. ${ }^{[57]}$ demonstrated that GIK therapy was beneficial in patients with unstable angina pectoris when it was given as adjunctive therapy before and 12 hours after coronary artery bypass graft (CABG) surgery. During the 18 -hour immediate postoperative period, the GIK group had a $40 \%$ higher cardiac index $(\mathrm{p}<0.001)$ despite receiving less inotropic drug support than a control group receiving standard therapy. The incidence of atrial fibrillation was also significantly reduced in the GIK recipients. Gradinac et al. ${ }^{[58]}$ have demonstrated beneficial effects of GIK therapy in the setting of postoperative cardiogenic shock after CABG surgery. In an initial trial of 22 consecutive patients, GIK therapy markedly decreased plasma FFA levels and increased cardiac index by nearly $40 \%$ in the first 12 hours without the need for increased inotropic drug use $(\mathrm{p}<0.005)$. In a somewhat larger trial, 322 postoperative CABG surgery patients with severe heart failure were randomized to GIK, GIK plus an amino acid supplement, or control. ${ }^{[59]}$ GIK therapy reduced in-hospital mortality by $34 \%$ and also reduced intensive care unit and total hospital length of stay.

There have been surprisingly few reports of adverse effects with GIK therapy, and most patients did not require central venous access. Electrolyte abnormalities are rare if frequent monitoring is performed. In the ECLA trial, ${ }^{[27]}$ there was no significant difference in serum glucose levels in the treatment group versus the control group at 6,24 , and 48 hours after randomization. Serum potassium levels were higher at 24 and 48 hours with GIK therapy; however, the increase was not clinically significant (serum potassium level was $4.24 \mathrm{mmol} / \mathrm{L}$ at 48 hours with GIK, and $4.08 \mathrm{mmol} / \mathrm{L}$ in controls). In the original high dose GIK trial of Rogers et al., ${ }^{[25]}$ significant hyperkalemia (serum potassium level $>6.0 \mathrm{mmol} / \mathrm{L}$ ) occurred in $10 \%$ of the treatment group and was generally managed by reducing the potassium concentration of the infusate. Hyperkalemia was seen almost exclusively in patients with oligurua or renal failure, and it also tended to be observed more commonly in patients with diabetes mellitus. ${ }^{[25]}$ Aside from the expected shifts in serum glucose and potassium levels, the most common adverse event is phlebitis at the site of peripheral intravenous line placement, however, severe phlebitis was 
observed in only $1.9 \%$ of patients in the ECLA trial. Other reported adverse events have included pulmonary congestion and pulmonary infiltration, which are rare and can be prevented by avoiding GIK administration in patients with oliguria (table II). ${ }^{[25]}$

Collectively, there are strong data to support the use of GIK in patients with acute myocardial infarction treated with reperfusion therapy and in the perioperative period for patients undergoing CABG surgery. Substantial data also support the use of GIK in acute myocardial infarction treated without reperfusion therapy, particularly in patients with diabetes mellitus. Potential therapeutic uses for GIK in the future might include cardiac protection during percutaneous coronary intervention, unstable angina pectoris, cardiogenic shock, and congestive heart failure due to ischemic cardiomyopathy, although clinical data to support these uses are currently not available. A lack of proprietary interest by the pharmaceutical industry has perhaps hampered the development of this otherwise promising therapy.

\subsection{L-Carnitine}

Carnitine is a 7-carbon organic amine that is required as a cofactor in the transport of long-chain fatty acids from the cytoplasm into the mitochondrial matrix. It exists in dextro $(D)$ and levo $(L)$ stereoisomers, however the $D$-isomer is metabolically inert. Two congeners of $L$-carnitine are known, acetyl$L$-carnitine and propionyl- $L$-carnitine, but they have slightly different metabolic effects to $L$-carnitine itself (fig. 3). ${ }^{[60]}$ $L$-carnitine is synthesized primarily in the liver and the kidney from the amino acid precursors lysine and methionine. Serum levels of $L$-carnitine peak 3 to 9 hours after an oral dose and almost immediately following intravenous administration. The bioavailability of oral $L$-carnitine ranges from 20 to $87 \%$, and it is cleared from the plasma primarily as acylcarnitine by renal excretion. ${ }^{[60]}$

Since fatty acid oxidation within the mitochondria is the primary source for ATP production in the myocardium, the transport function of $L$-carnitine has been proposed to be critical to the maintenance of proper cardiac function. ${ }^{[61]}$ In the presence of $L$-carnitine, the enzyme carnitine palmitoyl transferase (CPT-1) transfers fatty acyl groups from acyl coenzyme A to $L$-carnitine, forming acyl carnitine. This carnitine/fatty acid complex (acyl carnitine) is then transported through the inner mitochondrial membrane into the mitochondrial matrix where it may be used to generate ATP (fig. 4).

In addition to this vital fatty acid transport function, carnitine also stimulates carbohydrate metabolism, a role that may
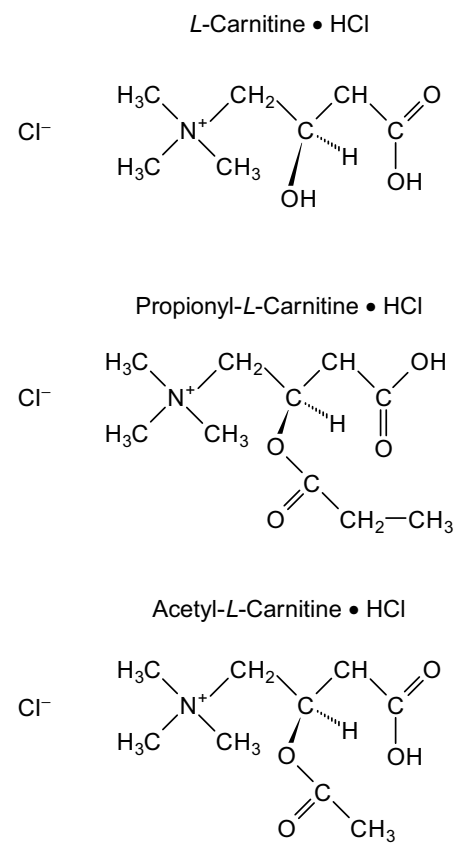

Fig. 3. Chemical structures of $L$-carnitine, propionyl- $L$-carnitine, and acetyl- $L-$ carnitine.

become critically important under conditions of ischemia when the oxidation of glucose becomes more efficient than oxidation of FFA. Further metabolic effects of $L$-carnitine in cardiac ischemia include improvement in pyruvate metabolism, reduced lactate production and acidosis, and scavenging of toxic catabolic products of FFA that accumulate rapidly during active ischemia. ${ }^{[62]}$ In animal models of cardiac ischemia, $L$-carnitine supplementation has been shown to prevent the loss of high-energy phosphate stores, preserve mitochondrial, mechanical, and electrocardiographic function, and prevent tissue necrosis. Furthermore, propionyl- $L$-carnitine has been demonstrated to function as a scavenger of free radicals in the setting of ischemia-reperfusion. ${ }^{[63]}$

$L$-Carnitine is normally found in high levels in cardiac and skeletal muscle; however, these muscles are incapable of synthesizing it themselves, relying on the liver and kidneys for production, in addition to dietary intake. During myocardial ischemia and heart failure, myocardial $L$-carnitine levels diminish rapidly, often despite elevated circulating levels of $L$ carnitine in the plasma. ${ }^{[64,65]}$ Animal models of experimental ischemia have also demonstrated reduced levels of myocardial $L$-carnitine. While myocardial $L$-carnitine stores are rapidly depleted in the setting of ischemia, exogenous administration of $L$-carnitine may prevent adverse effects related to relative $L$-carnitine deficiency. Administration of $L$-carnitine has been 
shown to improve myocardial oxidative metabolism, prevent cardiac dilation and preserve left ventricular function after myocardial infarction (table III).

The clinical use of $L$-carnitine has been proposed for a wide range of cardiovascular disorders, including angina pectoris, acute ischemic syndromes, myocardial infarction, arrhythmia, congestive heart failure, peripheral vascular disease, hyperlipidemia, and also diabetes mellitus. In addition, $L$-carnitine has been proposed as a myocardial protectant during cardiac surgery. While animal and experimental in vivo data are substantial, clinical trials using $L$-carnitine supplementation have been small and underpowered to show substantive effects on mortality and other hard clinical end-points. A recent small trial by Singh et al. ${ }^{[28]}$ investigated the use of oral $L$-carnitine $(2 \mathrm{~g} /$ day for 28 days, $\mathrm{n}=51)$ or placebo $(\mathrm{n}=50)$ in patients with suspected acute myocardial infarction (table I). At 28 days, rise in total serum creatine kinase levels, episodes of angina pectoris, incidence of arrhythmia, and NYHA class were all significantly less in the $L$-carnitine group compared with placebo.

Two recent larger clinical trials are beginning to shed more light on the use of $L$-carnitine in acute myocardial infarction. The Carnitina Ecocardiografia Digitalizzata Infarto Miocardico (CEDIM) Trial enrolled 472 patients within 24 hours of their first acute anterior wall myocardial infarction. ${ }^{[29]}$ The primary end-point was echocardiographically determined left ventricular volumes and ejection fraction at 12 months. Patients were randomized to receive placebo or $L$-carnitine $(9 \mathrm{~g} /$ day continuous intravenous infusion for 5 days followed by oral administration of $2 \mathrm{~g} 3$ times daily for 12 months), and $80 \%$ of patients in each group received thrombolytic therapy. Left ventricular volume measurements were made by echocardiography at baseline and at 3, 6, and 12 months. Left ventricular end-systolic and end-diastolic volumes were significantly lower at the 3-, 6-, and 12-month follow-ups in patients receiving $L$-carnitine compared with control patients. There was a further nonsignificant trend toward reduced mortality and development of clinical heart failure at 12 months in the group receiving $L$-carnitine. The results of this trial have prompted the initiation of the CEDIM-2 Trial, which will randomize 4000 patients with acute myocardial infarction to $L$-carnitine or placebo, with the primary end-point being 6month combined incidence of death or development of chronic heart failure. ${ }^{[30]}$ This would be, by far, the largest trial ever performed using $L$-carnitine and it is hoped it will answer important questions related to effects on substantive clinical endpoints.
$L$-Carnitine administration appears to be quite well tolerated, with no reported adverse effects other than the development of a fish-like body odor with large doses. This effect is rare, appears to be dose-related, and is the most common reason for the discontinuation of therapy. Infrequently, instances of pyrosis, dyspepsia, visual blurring, and headache have been reported (table II). In a heart failure trial in 80 patients with dilated cardiomyopathy, Rizos ${ }^{[66]}$ found an $8 \%$ incidence of 'minor gastrointestinal problems' with oral administration of $L$-carnitine $2 \mathrm{~g} /$ day for 3 years. These adverse effects did not lead to study drug withdrawal in any patient. ${ }^{[66]}$ Most clinical studies with $L$-carnitine have reported a complete lack of adverse effects, and no major clinical toxicities have been noted.

\section{Future Directions}

The treatment of myocardial ischemia continues to be a challenge. Traditional methods of modifying oxygen consumption, such as reducing heart rate and blood pressure, may very well be enhanced by the addition of metabolically active drugs that work by the mechanisms described in this article. It seems that the most likely immediate application of drugs such as ranolazine and trimetazidine will be for the treatment of chronic angina pectoris, where they may be added to traditional therapy with minimal risk for adverse effects.

The treatment of myocardial infarction will continue to center around the rapid re-establishment and maintenance of coronary blood flow. It is unlikely that metabolically active drugs will ever replace this type of treatment. The morbidity and mortality associated with acute myocardial infarction remains unacceptably high, however, and given the theoretical and

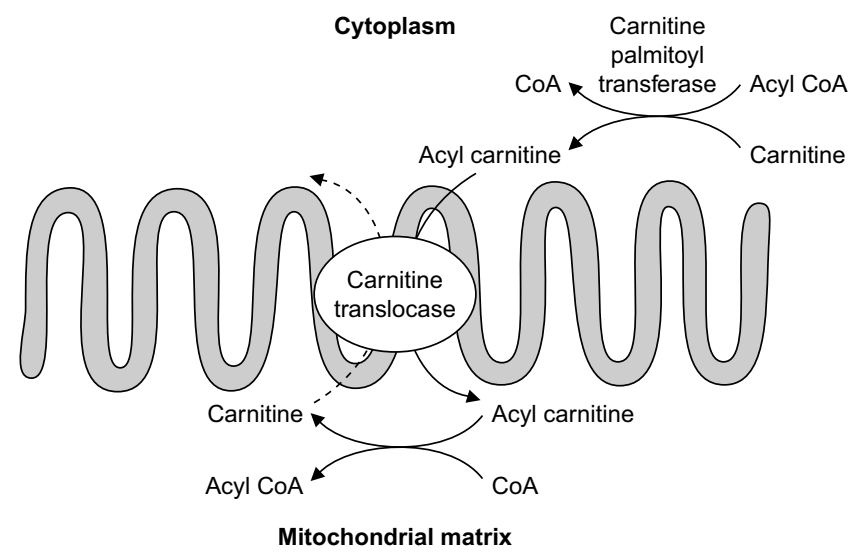

Fig. 4. Carnitine transport system: long chain fatty acids do not enter the mitochondrial matrix directly but rather bind to carnitine and are then shuttled into the mitochondrion (adapted from Arsenian, ${ }^{[60]}$ with permission). $\mathbf{C o A}=$ coenzyme A. 
Table III. Effects of $L$-carnitine supplementation in myocardial ischemia

\section{Metabolic effects}

Prevents the loss of high-energy phosphates

Preserves myocardial carnitine stores

Reduces the accumulation of toxic fatty acid esters

Enhances the oxidation of glucose

Improves the extraction of lactate

Physiologic effects

Reduces ST segment elevation

Reduces ventricular arrhythmias

Improves ventricular systolic and diastolic function

Reduces infarct size

proven clinical benefit of metabolically active agents, it would seem important to test them in larger clinical trials to assess their potential for incremental value in this setting. In particular, the adjunctive use of GIK therapy or $L$-carnitine have additive value in the traditional treatment of myocardial infarction.

Finally, as heart failure continues to increase in incidence and represents a growing public health concern, new agents that approach this problem from a unique perspective are to be welcomed. The potential ability of metabolically active drugs to enhance myocardial performance without adversely affecting hemodynamics is an area worthy of wider clinical evaluation.

\section{References}

1. De Jong JW, editor. Myocardial energy metabolism. Dordrecht: Martinuus Nijhoff Publishers, 1988

2. McCormack JG, Stanley WC, Wolff AA. Ranolazine: a novel metabolic modulator for the treatment of angina. Gen Pharmacol 1998; 30 (5): 639-45

3. Data on file, CV Therapeutics, Palo Alto (CA), 1999

4. McCormack JG, Baracos VE, Barr R, et al. Effects of ranolazine on oxidative substrate preference in epitrochlearis muscle. J Appl Physiol 1996 Aug; 81 (2): $905-10$

5. Clarke B, Wyatt KM, McCormack JG. Ranolazine increases active pyruvate dehydrogenase in perfused normoxic rat hearts: evidence for an indirect mechanism. J Mol Cell Cardiol 1996; 28 (2): 341-50

6. McCormack JG, Barr RL, Wolff AA, et al. Ranolazine stimulates glucose oxidation in normoxic, ischemic, and reperfused ischemic rat hearts. Circulation 1996 Jan; 93 (1): 135-42

7. Allely MC, Alps BJ. Prevention of myocardial enzyme release by ranolazine in a primate model of ischaemia with reperfusion. Br J Pharmacol 1990 Jan; 99 (1): 5-6

8. Gralinski MR, Black SC, Kilgore KS, et al. Cardioprotective effects of ranolazine (RS-43285) in the isolated perfused rabbit heart. Cardiovasc Res 1994 Aug; 28 (8): 1231-7

9. Black SC, Gralinski MR, McCormack JG, et al. Effect of ranolazine on infarct size in a canine model of regional myocardial ischemia/reperfusion. J Cardiovasc Pharmacol 1994 Dec; 24 (6): 921-8

10. Aaker A, McCormack JG, Hirai T, et al. Effects of ranolazine on the exercise capacity of rats with chronic heart failure induced by myocardial infarction. J Cardiovasc Pharmacol 1996 Sept; 28 (3): 353-62
11. Sabbah HN, Mishima T, Biesiadecki BJ, et al. Ranolazine improves left ventricular performance in dogs with chronic heart failure [abstract]. J Am Coll Cardiol 2000 Feb; 35 Suppl. A: 218A

12. Jain D, Dasgupta P, Hughes LO, et al. Ranolazine (RS-43285): a preliminary study of a new anti-anginal agent with selective effect on ischaemic myocardium. Eur J Clin Pharmacol 1990; 38 (2): 111-4

13. Thadani U, Ezekowitz M, Fenney L, et al. Double-blind efficacy and safety study of a novel anti-ischemic agent, ranolazine, versus placebo in patients with chronic stable angina pectoris: Ranolazine Study Group. Circulation 1994 Aug; 90 (2): 726-34

14. Cocco G, Rousseau MF, Bouvy T, et al. Effects of a new metabolic modulator, ranolazine, on exercise tolerance in angina pectoris patients treated with beta-blocker or diltiazem. J Cardiovasc Pharmacol 1992 Jul; 20 (1): 131-8

15. Pepine CJ, Wolff AA. A controlled trial with a novel anti-ischemic agent, ranolazine, in chronic stable angina pectoris that is responsive to conventional antianginal agents. Am J Cardiol 1999 Jul; 84 (1): 46-50

16. Wolff AA. MARISA: monotherapy assessment of ranolazine in stable angina [abstract]. J Am Coll Cardiol 2000 Feb; 35 Suppl. A: 408A

17. Kober G, Buck T, Sievert H, et al. Myocardial cytoprotection during percutaneous transluminal coronary angioplasty: effects of trimetazidine. Eur Heart J 1992; 13: 1109-15

18. Detry JM, Sellier P, Pennaforte S, et al. Trimetazidine: a new concept in the treatment of angina. Comparison with propranolol in patients with stable angina. Br J Clin Pharmacol 1994; 37: 279-88

19. Szwed H, Pachocki R, Domzal-Bochenska M, et al. Efficacy and tolerance of trimetazidine, a metabolic antianginal, in combination with a hemodynamic antianginal in stable exertion angina: TRIMPOL I, a multicenter study. Presse Med 2000; 29 (10): 533-8

20. Levy S, and the Group of South of France Investigators. Combination therapy of trimetazidine with diltiazem in patients with coronary artery disease. Am J Cardiol 1995; 76 Suppl. B: 12B-16B

21. Stacpoole PW, Harman EM, Curry SH, et al. Treatment of lactic acidosis with dichloroacetate. N Engl J Med 1983 Aug 18; 309 (7): 390-6

22. Stacpoole PW, Wright EC, Baumgartner TG, et al. A controlled clinical trial of dichloroacetate for treatment of lactic acidosis in adults: The Dichloroacetate-Lactic Acidosis Study Group. N Engl J Med 1992 Nov 26; 327 (22): 1564-9

23. Wargovich TJ, MacDonald RG, Hill JA, et al. Myocardial metabolic and hemodynamic effects of dichloroacetate in coronary artery disease. Am J Cardiol 1988 Jan 1; 61 (1): 65-70

24. Bersin RM, Wolfe C, Kwasman M, et al. Improved hemodynamic function and mechanical efficiency in congestive heart failure with sodium dichloroacetate. J Am Coll Cardiol 1994 Jun; 23 (7): 1617-24

25. Rogers WJ, Stanley AW, Breinig JB, et al. Reduction of hospital mortality rate of acute myocardial infarction with glucose-insulin-potassium infusion. Am Heart J 1976 Oct; 92 (4): 441-54

26. Malmberg K, Ryden L, Efendic S, et al. Randomized trial of insulin-glucose infusion followed by subcutaneous insulin treatment in diabetic patients with acute myocardial infarction (DIGAMI Study): effects on mortality at 1 year. J Am Coll Cardiol 1995 Jul; 26 (1): 57-65

27. Díaz R, Paolasso EA, Piegas LS, et al. Metabolic modulation of acute myocardial infarction: the ECLA (Estudios Cardiológicos Latinoamérica) Collaborative Group. Circulation 1998 Nov 24; 98 (21): 2227-34

28. Singh RB, Niaz MA, Agarwal P, et al. A randomised, double-blind, placebocontrolled trial of L-carnitine in suspected acute myocardial infarction. Postgrad Med J 1996 Jan; 72 (843): 45-50

29. Iliceto S, Scrutinio D, Bruzzi P, et al. Effects of L-carnitine administration on left ventricular remodeling after acute anterior myocardial infarction: the L-carnitine Ecocardiografia Digitalizzata Infarto Miocardico (CEDIM) Trial. J Am Coll Cardiol 1995 Aug; 26 (2): 380-7 
30. Colonna P, Iliceto S. Myocardial infarction and left ventricular remodeling: results of the CEDIM trial: Carnitine Ecocardiografia Digitalizzata Infarto Miocardico. Am Heart J 2000 Feb: 139 (2 Pt 3): S124-30

31. Desideri A, Celegon L. Metabolic management of ischemic heart disease: clinical data with trimetazidine. Am J Cardiol 1998 Sept 3; 82 Suppl. K: 50K-53K

32. McClellan KJ, Plosker GL. Trimetazidine: a review of its use in stable angina pectoris and other coronary conditions. Drugs 1999 Jul; 58 (1): 143-57

33. Harpey C, Clauser P, Labrid C, et al. Trimetazidine, a cellular anti-ischemic agent. Cardiovasc Drug Rev 1989; 6 (4): 292-312

34. Goupit P. Pharmacocinetique de la trimetazidine. Concours Med 1987; 109 Suppl. 36: 3447-51

35. Lavanchy N, Martin J, Rossi A. Anti-ischemic effects of trimetazidine: ${ }^{31} \mathrm{P}$ NMR spectroscopy in the isolated rat heart. Arch Intern Pharmacodyn Ther 1987; 289: 97-110

36. Drake-Holland AJ, Belcher PR, Hynd J, et al. Infarct size in rabbits: a modified method illustrated by effects of propranolol and trimetazidine. Basic Res Cardiol 1993; 88: 250-8

37. Maridonneau-Parini I, Harpey C. Effects of trimetazidine on membrane damage induced by oxygen free-radicals in human cells. Br J Clin Pharmacol 1985; 20: 148-51

38. Fabiani JN, Ponzio O, Emerit I, et al. Cardioprotective effect of trimetazidine during coronary artery graft surgery. J Cardiovasc Surg 1992; 38: 486-91

39. Brottier L, Barat JL, Combe C, et al. Therapeutic value of a cardioprotective agent in patients with severe ischemic cardiomyopathy. Eur Heart J 1990; 11: $207-12$

40. Rogacka D, Guzik P, Wykretowicz A, et al. Effects of trimetazidine on clinical symptoms and tolerance of exercise of patients with Syndrome X: a preliminary study. Coron Artery Dis 2000 Mar; 11 (2): 171-7

41. Dalla-Volta S, Maraglino G, Della-Valentina $P$, et al. Comparison of trimetazidine with nifedipine in effort angina: a double-blind, crossover study. Cardiovasc Drugs Ther 1990 Aug; 4 Suppl. 4: 853-9

42. Pohl L, Nelson S, Krishna G. Investigation of the mechanism of the metabolic activation of chloramphenicol by rat liver microsomes: identification of a new metabolite. Biochem Pharmacol 1978 Feb; 27 (4): 491-6

43. Greenstein L, Hitt B, Mazze R. Metabolism in vitro of enflurane, isoflurane, and methoxyflurane. Anesthesiology 1975 Apr; 42 (4): 420-4

44. Curry SH, Lorenz A, Chu P, et al. Disposition and pharmacodynamics of dichloroacetate (DCA) and oxalate following oral DCA doses. Biopharm Drug Dispos 1991 Jul; 12 (5): 375-90

45. Burns AH, Giaimo ME, Summer WR. Dichloroacetic acid improves in vitro myocardial function following in vivo endotoxin administration. J Crit Care 1986; 1: 11-17

46. Mjos OD, Miller NE, Riemersma RA, et al. Effects of dichoroacetate on myocardial substrate extraction, epicardial ST-segment elevation, and ventricular blood flow following coronary occlusion in dogs. Cardiovasc Res 1976; 10: $427-36$

47. McVeigh JJ, Lopaschuk JD. Dichloroacetate stimulation of glucose oxidation improves recovery of ischemic rat hearts. Am J Physiol 1990; 259 Suppl. H: 1079-85

48. Ludvik B, Peer G, Berzlanovich A, et al. Effects of dichloroacetate and bicarbonate on haemodynamic parameters in healthy volunteers. Clin Sci (Colch) 1991 Jan; 80 (1): 47-51

49. Moore GW, Swift LL, Rabinowitz D, et al. Reduction of serum cholesterol in two patients with homozygous familial hypercholesterolemia by dichloroacetate. Atherosclerosis 1979; 33: 285-93
50. Apstein CS. Increased glycolytic substrate protection improves ischemic cardiac dysfunction and reduces injury. Am Heart J 2000 Feb; 139 (2 Pt 3): S107-14

51. Oliver MF, Opie LH. Effects of glucose and fatty acids on myocardial ischaemia and arrhythmias. Lancet 1994 Jan 15; 343 (8890): 155-8

52. Opie LH. Free fatty acids and acute myocardial infarction [letter]. Lancet 1974 Oct 12; 2 (7885): 903

53. Eberli FR, Weinberg EO, Grice WN, et al. Protective effect of increased glycolytic substrate against systolic and diastolic dysfunction and increased coronary resistance from prolonged global underperfusion and reperfusion in isolated rabbit hearts perfused with erythrocyte suspensions. Circ Res 1991 Feb; 68 (2): 466-81

54. Sodi-Pallares D, Testelli M, Fishleder F. Effects of an intravenous infusion of a potassium-insulin-glucose solution on the electrocardiographic signs of myocardial infarction. Am J Cardiol 1962; 9: 166-81

55. Rackley CE, Russell RO, Rogers WJ, et al. Clinical experience with glucoseinsulin-potassium therapy in acute myocardial infarction. Am Heart J 1981 Dec; 102 (6 Pt 1): 1038-49

56. Fath-Ordoubadi F, Beatt KJ. Glucose-insulin-potassium therapy for treatment of acute myocardial infarction: an overview of randomized placebo-controlled trials. Circulation 1997 Aug 19; 96 (4): 1152-6

57. Lazar HL, Philippides G, Fitzgerald C, et al. Glucose-insulin-potassium solutions enhance recovery after urgent coronary artery bypass grafting. J Thorac Cardiovasc Surg 1997 Feb; 113 (2): 354-62

58. Gradinac $\mathrm{S}$, Coleman GM, Taegtmeyer $\mathrm{H}$, et al. Improved cardiac function with glucose-insulin-potassium after aortocoronary bypass surgery. Ann Thorac Surg 1989 Oct; 48 (4): 484-9

59. Taegtmeyer H, Goodwin GW, Doenst T, et al. Substrate metabolism as a determinant for postischemic functional recovery of the heart. Am J Cardiol 1997 Aug 4; 80 (3 Suppl. A): 3A-10A

60. Arsenian MA. Carnitine and its derivatives in cardiovascular disease. Prog Cardiovasc Dis 1997 Nov-Dec; 40 (3): 265-86

61. Lopaschuk G. Regulation of carbohydrate metabolism in ischemia and reperfusion. Am Heart J 2000 Feb; 139 (2 Pt 3): S115-9

62. Chierchia SL, Fragasso G. Metabolic management of ischaemic heart disease. Eur Heart J 1993 Nov; 14 Suppl. G: 2-5

63. Packer L, Valenza M, Serbinova E, et al. Free radical scavenging is involved in the protective effect of L-propionyl-carnitine against ischemiareperfusion injury of the heart. Arch Biochem Biophys 1991 Aug 1; 288 (2): $533-7$

64. Spagnoli LG, Corsi M, Villaschi S, et al. Myocardial carnitine deficiency in acute myocardial infarction [letter]. Lancet 1982 Jun 19; I (8286): 1419-20

65. Regitz V, Shug AL, Fleck E. Defective myocardial carnitine metabolism in congestive heart failure secondary to dilated cardiomyopathy and to coronary, hypertensive and valvular heart diseases. Am J Cardiol 1990 Mar 15; 65 (11): 755-60

66. Rizos I. Three-year survival of patients with heart failure caused by dilated cardiomyopathy and L-carnitine administration. Am Heart J 2000 Feb: 139 (2 Pt 3): S120-3

Correspondence and offprints: Dr Richard S. Schofield, 1600 Archer Road, P.O. Box 100277, Gainesville, FL 32610-0277, USA.

E-mail: schofrs@medicine.ufl.edu 